\title{
Question the unquestionable
}

Masahiko Ando, MD, PhD, MPH, Marisa Cevasco, MD, MPH, and Hiroo Takayama, MD, PhD

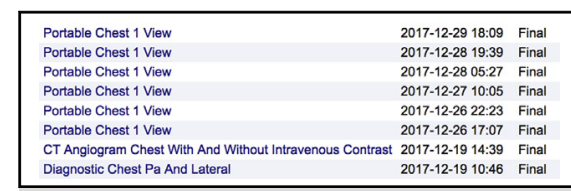

Was this radiology package too much for a young healthy man with a root replacement?

Central Message

Given escalating health care costs in the United States, the utility of each aspect of clinical care must be closely examined.

See Article page 2035.
Health care costs in the United States are growing at an
unsustainable rate. ${ }^{1}$ In light of this, health care policymakers and clinicians must investigate the rationale behind each step of daily practice. Fittingly, den Harder and colleagues ${ }^{2}$ addresses the utility of the routine preoperative chest $\mathrm{x}$-ray in this month's Journal. These chest X-rays cost on average $\$ 31$ per film, and along with an electrocardiogram are considered de rigueur for preoperative cardiac surgery workup. Despite their seeming indispensability, these $\mathrm{x}$-rays lead to significant change in surgical planning in just $0.3 \%$ of patients. So is this practice justified?

In low-risk, noncardiac surgery, a preoperative chest $\mathrm{x}$-ray is no longer recommended, and perhaps this may be applied to patients undergoing coronary artery bypass grafting and other straightforward cardiac surgical procedures. ${ }^{3}$ Of course, we would still need more evidence to build guideline-level recommendations.

Physicians are uniquely positioned to take a leading role in maximizing the efficiency of clinical practice and reducing health care costs, yet we are often faced with patients' requests for additional studies and interventions. ${ }^{4}$ In an effort to promote dialogue between physicians and patients about making reasonable choices and reducing unnecessary health care spending, the American Board of Internal Medicine Foundation established the "Choosing Wisely" initiative in 2012. "The Society of Thoracic Surgery quickly joined the campaign, highlighting examples such as preoperative pulmonary function testing and carotid ultrasonography in asymptomatic patients as overused tests. Given the findings from den Harden and colleagues' article, the preoperative chest $\mathrm{x}$-ray may go the same way as the formerly obligatory. ${ }^{5}$

Regardless of cost efficiencies, there are several intangible yet crucial nuances generated from a preoperative chest $\mathrm{x}$-ray. Chest $\mathrm{x}$-rays are an essential component of anesthesia planning, and they may be used in postoperative care as an important baseline. How many of us would feel comfortable taking care of a patient after a coronary artery bypass grafting or valve surgery with no baseline chest $\mathrm{x}$-ray? In the present study, the chest $\mathrm{x}$-ray was only considered "useful" when it prompted an action or intervention before surgery. This narrow definition may underestimate the utility of a chest $\mathrm{x}$-ray for surgeons who closely study it and modify their routine surgical approach. For instance, the lateral view in a preoperative chest $\mathrm{x}$-ray in a patient about to undergo a reoperative sternotomy may demonstrate a tight space between the aorta and the posterior sternum, and a surgeon may consider peripheral cannulation without delaying the planned surgery.

Nonetheless, this article by den Harder and colleagues ${ }^{2}$ is an important springboard for further discussion on cost-benefit issues facing cardiothoracic surgery. These issues both encompass and transcend the routine preoperative chest $\mathrm{x}$-ray, and will help push us toward creating consensus guidelines. From a bird's eye view, questioning the unquestionable (like the humble preoperative chest X-ray) is undoubtedly a healthy initiative, not only to reduce health care costs but also to improve patient care.

\section{References}

1. Berwick DM, Hackbarth AD. Eliminating waste in US health care. JAMA. 2012; 307:1513-6.

2. den Harder AM, de Heer LM, de Jong PA, Suyker WJ, Leiner T, Budde RPJ. Frequency of abnormal findings on routine chest radiography before cardiac surgery. J Thorac Cardiovasc Surg. 2018;155:2035-40.

3. Feely MA, Collins CS, Daniels PR, Kebede EB, Jatoi A, Mauck KF. Preoperative testing before noncardiac surgery: guidelines and recommendations. Am Fam Physician. 2013;87:414-8.

4. Cassel CK, Guest JA. Choosing wisely: helping physicians and patients make smart decisions about their care. JAMA. 2012;307:1801-2.

5. Wood DE, Mitchell JD, Schmitz DS, Grondin SC, Ikonomidis JS, Bakaeen FG, et al. Choosing wisely: cardiothoracic surgeons partnering with patients to make good health care decisions. Ann Thorac Surg. 2013;95:1130-5. 